\title{
Importance of incorporating teaching of feedback skills into medical curricula
}

This article was published in the following Dove Press journal:

Advances in Medical Education and Practice

22 April 2016

Number of times this article has been viewed

\section{Silvia Allikmets' \\ Jasper Vink ${ }^{2}$}

'King's College London School of Medicine, ${ }^{2}$ Imperial College London

School of Medicine, London, UK
Correspondence: Silvia Allikmets King's College London School of Medicine, 165 Great Dover Street, London SEI 4XA, UK Email silvia.allikmets@kcl.ac.uk

\section{Dear editor}

In the study by Burgess and Mellis, ${ }^{1}$ the importance of feedback in the learning process of the medical students has been discussed. The teaching of the medical students carries immense significance throughout their clinical career. At university, students learn skills that are embedded into their attitudes and behaviors for many years to come. Furthermore, these skills, in effect, become second nature to them, making them harder to adapt later. Therefore, it is important to equip students with the correct feedback skills and techniques early in their education. We agree with the conclusions drawn by Burgess and Mellis ${ }^{1}$ that feedback is crucial for learning and that the teaching of feedback skills should be a core component of medical education programs. However, despite their crucial significance, we believe that feedback skills are not adequately taught and practiced in medical schools.

The study of medicine is a balance of theoretical, scientific knowledge obtained through lectures or books and clinical skills gained through empirical observation and participation. Clinical skills are best learned through guidance from experienced supervisors and feedback that the students can build upon. Unfortunately, this is currently not being adequately delivered in clinical settings. For example, according to the data gathered from the National Student Survey on the undergraduate medicine programs in Bristol, Edinburgh, and Cardiff, only $30 \%, 30 \%$, and $40 \%$ of students, respectively, found that the feedback they received on their work helped clarify things they did not understand. ${ }^{2-4}$ The deficiency of helpful feedback could be due to the lack of appropriate education received by the teachers themselves (eg, clinical doctors) during their time in the medical school regarding how to provide feedback. As universities educate students to become competent doctors of the future, it falls within the duties of faculties to ensure that the future doctors will be able to provide adequate feedback later in their careers, especially when training the next generation of the medical students. Therefore, feedback should be implemented as an essential part of medical education at the university level.

Additionally, Burgess and Mellis ${ }^{1}$ make an interesting point that receiving feedback should not be considered as a passive act. Algiraigri ${ }^{5}$ states that the lack of student empowerment inhibits them from using received feedback appropriately and further suggests that this may be due to the hierarchical nature of educational institutions. This implies that students are often placed into a position of passive participation in the feedback process, rather than being active members who take ownership of the

submit your manuscript | www.dovepress.con 
received feedback. Crucially, in order for feedback to take strong effect, a behavioral change must be invoked, which is only attainable through student involvement. To achieve this, besides being taught how to give feedback, students should be guided on how to understand and utilize the feedback that they are given in order to benefit their own learning experiences.

As the importance of feedback is increasingly recognized, some medical faculties are now teaching certain teaching skills to the students, including feedback giving, in their undergraduate programs. ${ }^{6}$ However, Kruidering-Hall et $\mathrm{al}^{7}$ found that the specificity of student feedback fell over time, before and after the students were taught how to deliver feedback, implying that the ability to provide high-quality, specific feedback can be a complicated skill to learn and requires consistent teaching and evaluation. This notion is further strengthened by other studies where incorporating feedback in an attempt to aid students in learning clinical skills was unsatisfactory. ${ }^{8,9}$ The relatively unsuccessful use of feedback in these studies could be the direct result of students not being taught to give or receive effective feedback, thereby making the exercise of incorporating feedback useless. This highlights a problem that needs to be addressed actively by universities in improving their medical curricula, especially as there is growing evidence to indicate that the medical students feel that the use of feedback can be helpful and beneficial in their own learning of certain clinical skills, for example, anatomy ${ }^{10}$ or professionalism. ${ }^{11}$

In conclusion, it is important for the medical students to be taught feedback skills as well as how to process feedback in an objective manner and transpose this to benefit their own knowledge and clinical skills. To obtain these goals, we believe that there must be a structural change in the methods in which medical education is provided to incorporate a strong focus on teaching students how to provide and receive feedback. Furthermore, as the literature is lacking where teaching methods of feedback skills in medical education is concerned, we believe that there is a need for further studies to assess the concerns voiced earlier.

\section{Disclosure}

The authors report no conflicts of interest in this communication.

\section{References}

1. Burgess A, Mellis C. Feedback and assessment for clinical placements: achieving the right balance. Adv Med Educ Pract. 2015;6:373-381.

2. MBBCh (Hons) Medicine Cardiff University [webpage on the Internet]. Unistats. Available from: https://unistats.direct.gov.uk/Subjects/ Overview/10007814FT-UFBHMEDA/ReturnTo/Search. Accessed March 1, 2016.

3. MBChB (Hons) Medicine University of Edinburgh [webpage on the Internet]. Unistats. Available from: https://unistats.direct.gov.uk/Subjects/Overview/10007790FT-UTMBCHBMDP1F/ReturnTo/Search. Accessed March 1, 2016.

4. MBChB (Hons) Medicine University of Bristol [webpage on the Internet]. Unistats. Available from: https://unistats.direct.gov.uk/Subjects/ Overview/10007786FT-8MDYF001UU-201415/ReturnTo/Search. Accessed March 1, 2016.

5. Algiraigri AH. Ten tips for receiving feedback effectively in clinical practice. Med Educ Online. 2014;19:25141.

6. Tanna R, Patel N. Improving the quality of feedback given to medical students. Adv Med Educ Pract. 2015;6:633-634.

7. Kruidering-Hall M, O'Sullivan PS, Chou CL. Teaching feedback to first-year medical students: long-term skill retention and accuracy of student self-assessment. J Gen Intern Med. 2009;24(6):721-726.

8. Maguire P, Roe P, Goldberg D, Jones S, Hyde C, O'Dowd T. The value of feedback in teaching interviewing skills to medical students. Psychol Med. 1978;8(4):695-704.

9. Uhm S, Lee GH, Jin JK, Bak YI, Jeoung YO, Kim CW. Impact of tailored feedback in assessment of communication skills for medical students. Med Educ Online. 2015;20:28453.

10. Gukas ID, Miles S, Heylings DJ, Leinster SJ. Medical students' perceptions of peer feedback on an anatomy student-selected study module. Med Teach. 2008;30(8):812-814.

11. Camp CL, Gregory JK, Lachman N, Chen LP, Juskewitch JE, Pawlina W. Comparative efficacy of group and individual feedback in gross anatomy for promoting medical student professionalism. Anat Sci Educ. 2010;3(2):64-72. 


\section{Authors' reply \\ Annette Burgess' \\ Craig Mellis ${ }^{2}$}

'Education Office, Sydney Medical School, The University of Sydney, Sydney, NSW, Australia.

${ }^{2}$ Sydney Medical School - Central, The University of Sydney. Sydney, NSW, Australia

Correspondence: Annette Burgess

Central Clinical School, Sydney Medical School, The University of Sydney,

Building 63, Level 4, Royal Prince

Alfred Hospital, Missenden Road, Camperdown, Sydney, NSW 2050,

Australia

Tel +6I 295158172

Email annette.burgess@sydney.edu.au

We appreciate Allikmets and Vink's interest in our article on 'Feedback and assessment for clinical placements'. ${ }^{1}$ We thank them for their constructive comments and contribution to the discussion on the importance of feedback in the medical students' learning process. We agree that skills in giving and receiving feedback are often not adequately taught and consistently practiced during medical school. Further, as well as being taught how to give feedback, students need to practice feedback, throughout their medical course. At Sydney Medical School, we have achieved this through our formal Peer Assisted Learning (PAL) program, which consists of five student-centered activities: teacher training;, ${ }^{2,3}$ peer assessment in practice objective structured clinical examinations, ${ }^{4}$ peer assessment in formative long cases, ${ }^{5-8}$ peers as simulated patients, ${ }^{9}$ and peer tutoring. ${ }^{10}$ Informed by PAL literature, the design of the PAL program provides a framework within which students can practice and improve their medical knowledge, teaching and feedback skills, which helps to shape students professional values as they move toward medical practice. The PAL program enables students to take on teaching, assessment, feedback and learning roles within the "safety" of their medical school. Results from our evaluations demonstrate that students feel supported by their medical school community, better prepared for their summative written and clinical assessments, and better prepared for their future careers as medical practitioners where they will be required to teach, assess, supervise and provide feedback to their peers. Participation has created a dynamic social learning network, engaging hospital clinicians, academics and students across all years. ${ }^{11}$ Our program has received three prestigious awards, including a 2013 Vice-Chancellor's Award for Support of the Student Experience, 2014 Australian Award for University Teaching: Citation for Outstanding Contributions to Student Learning, and 2015 Australian Award for University Teaching: Awards for Programs that Enhance Learning.

\section{Disclosure}

The authors report no conflicts of interest in this communication.

\section{References}

1. Burgess A, Mellis C. Feedback and assessment for clinical placements: achieving the right balance. Adv Med Educ Pract. 2015;6:373-381.

2. van Diggele C, Burgess A, Mellis C. Teacher training program for medical students: improvements needed. Adv Med Educ Pract. 2015;6:265-270.

3. Burgess A, Black K, Chapman R, Clark T, Roberts C, Mellis C. Teaching skills for students: our future educators. Clin Teach. 2012;9:312-316.

4. Burgess A, Clark T, Chapman R, Mellis C. Senior medical students as peer examiners in an OSCE. Med Teach. 2013;35(1):58-62.

5. Burgess A, Roberts C, Black K, Mellis C. Senior medical student perceived ability and experience in giving feedback in formative long case examinations. BMC Med Educ. 2013;13:79.

6. Burgess A, Mellis C. Receiving feedback from peers: Medical students' perceptions. Clin Teach. 2015;12:203-207.

7. Burgess A, Roberts C, Black K, Mellis C. Student ability to assess peers in long case clinical examination. International Journal of Clinical Skills. 2014;8(1),14-19.

8. Burgess A, Roberts C, Black K, Mellis C. Student ability and learning experience in assessing peers alongside supervisors in the long case. Focus on health professional education: a multi-disciplinary journal. 2015;16(2):27-41.

9. Burgess A, Clark T, Chapman R, Mellis, C. Medical student experience as simulated patients in the OSCE. Clin Teach. 2013;10:246-250.

10. Burgess A, Dornan T, Clarke A, Menezes A, Mellis C. Peer Tutoring in a medical school: perceptions of tutors and tutees. BMC Med Educ. 2016:16:85

11. Burgess A, Nestel D. Facilitating development of professional identity through peer assisted learning in medical education. Adv Med Educ Pract. 2014;6:1-4.

Dove Medical Press encourages responsible, free and frank academic debate. The content of the Advances in Medical Education and Practice 'letters to the editor' section does not necessarily represent the views of Dove Medical Press, its officers, agents, employees, related entities or the Advances in Medical Education and Practice editors. While all reasonable steps have been taken to confirm the content of each letter, Dove Medical Press accepts no liability in respect of the content of any letter, nor is it responsible for the content and accuracy of any letter to the editor.

\section{Publish your work in this journal}

Advances in Medical Education and Practice is an international, peerreviewed, open access journal that aims to present and publish research on Medical Education covering medical, dental, nursing and allied health care professional education. The journal covers undergraduate education, postgraduate training and continuing medical education
Dovepress

including emerging trends and innovative models linking education, research, and health care services. The manuscript management system is completely online and includes a very quick and fair peer-review system. Visit http://www.dovepress.com/testimonials.php to read real quotes from published authors.

Submit your manuscript here: http://www.dovepress.com/advances-in-medical-education-and-practice-journal 